\title{
The Evolution of Communicative Intentions During Change Episodes and Throughout the Therapeutic Process
}

\author{
Paula Dagnino ${ }^{1,2 \varpi}$, Mariane Krause ${ }^{3}$, Carola Pérez ${ }^{4}$, Nelson Valdés $^{3}$, \& Alemka Tomicic ${ }^{4}$
}

\begin{abstract}
The present study examines the heterogeneity of the therapeutic process through the analysis of the conversation between therapists and clients in psychotherapy. The Communicative Intentions dimension of the Therapeutic Activity Coding System (TACS) was applied to 69 change episodes taken from 100 sessions that belong to five brief psychotherapies. Depending on what the participants are trying to achieve with their communication, the TACS distinguishes three types of Communicative Intentions: Exploring, Attuning, and Resignifying. Client and therapist verbalizations corresponding to these categories were analysed searching for differences between (a) both speakers, (b) initial, middle and final change episode stages, and (c) initial, middle and final phases of the whole therapeutic process. Results indicate that, in general, therapists resignify and attune more frequently, while clients explore more often. The analysis of Communicative Intentions within change episodes and during the whole therapeutic process reveals that there is an evolution in both: Even small therapy segments, as change episodes are, show that the process is not homogeneous, since in initial stages, the use of Exploring is more frequent than the use of Resignifying, especially for clients, while during the end of the episode clients and therapists increase their use of Resignifying. The analysis of the whole process confirms that Resignifying surpasses the use of Exploring in the final phases of therapy.
\end{abstract}

Keywords: therapeutic verbal communication, communicative actions, change episodes, therapeutic process

Progress in psychotherapy has been shown to be seldom smooth. There are ups and downs, moments of intensity, of reduced pace, and even interruptions (Detert, Llewelyn, Hardy, Barkham, \& Stiles, 2006), resembling a saw tooth pattern (Gabalda, 2006). The focus of this paper is on describing this irregularity in terms of what clients and therapists are doing throughout the therapeutic process, specifically in

\footnotetext{
${ }^{1}$ Universidad Gabriela Mistral, Department of Psychology, Santiago, Chile.

2 Pontificia Universidad Católica de Chile, Department of Psychiatry, Santiago, Chile.

3 Pontificia Universidad Católica de Chile, Department of Psychology, Santiago, Chile.

${ }^{4}$ Universidad del Desarrollo, Department of Psychology, Santiago, Chile.

Correspondence concerning this article should be addressed to Paula Dagnino, Pontificia Universidad Católica de Chile, Department of Psychology, Avda. Vicuña Mackenna 4860, Macul, Santiago, Chile.E-mail: pauladagnino@gmail.com
}

the specific components of their conversation. Psychotherapeutic interaction processes should be reflected in language and in the verbalizations of the speakers involved. This paper will follow a performative conception of language, according to which "to say something is to do something" (Reyes et al., 2008). Here, language is the vehicle for change, hence the importance of studying it.

Of the dimensions that can be studied in verbal communication, communicative purpose is the most interesting for understanding the interactive construction process of psychic change, regarded as that which takes place in subjective patterns of interpretation and explanations that lead to the development of new subjective theories (Krause, 2005, 2011).

The present article analyses how a specific type of these communicative actions, the communicative purpose of the speaker's utterances-their Communicative Intentions-evolve through the therapeutic process. The aim of the study performed was to as- 
sess the evolution of this specific type of communicative actions on a microanalytic level, during change episodes as well as during the whole therapeutic process. In addition to the existing knowledge in psychotherapy, this research intends to provide evidence regarding how therapeutic communication relates to change. By using this evidence clinicians may monitor both their their own and their clients' language and be alert to whether or not their communicative actions favour the change process.

\section{Research on therapeutic conversation}

The growing interest in understanding therapeutic conversation between therapist and client is highlighted by the recent emergence of several systems for classifying their verbal communication during therapeutic interactions. Some of these classification systems were constructed for a specific therapeutic approach, i.e. to measure therapist adherence to manuals, or to address specific therapeutic problems (Elkin, Parloff, Hadley, \& Autrey, 1985; Evans, Piasecki, Kriss, \& Hollon, 1984; Trijsburg et al., 2002). Other measures are of a more generic nature, but focus mainly on therapists' activity, for example on their communication or techniques (Elliott, 1984; Goldberg et al., 1984; Hill, 1978; Mahrer, Nadler, Stalikas, Schachter, \& Sterner, 1988; Watzke, Koch, \& Schulz, 2006). Generic classification systems are suitable for different therapeutic approaches and client problems and for classifying verbal communication by both therapist and client. One of them is Stiles' Verbal Response Taxonomy (VRM; Stiles, 1992) which measures eight basic response modes: Interpretation, Question, Reflection, Acknowledgment, Advisement, Disclosure, Confirmation and Edification. Another generic classification system, the Therapeutic Activity Coding System (TACS; Valdés, Tomicic, Pérez, \& Krause, 2010), includes five dimensions for classifying verbal communication-Basic Form, Communicative Intention, Technique, Domain and Reference-which can be used in combination or alone, depending on the research questions addressed.

In the TACS, client and/or therapist verbalizations are called communicative actions since they "fulfil a double purpose of bearing information (communication) and exercising an influence over the other participant and the realities created by both (action)" (Krause, Valdés, \& Tomicic, 2010, p. 2). Of the different dimensions of communicative actions distinguished in the TACS, the Communicative Intention is the facet of speech that specifically expresses the speaker's communicative purpose, and is thus closer to the action aspect of communication. In the case of the present study, which targets the evolution of the purposes involved in communication during the therapeutic process, the Communicative Intention dimension is the best match for this aim.

The TACS distinguishes three Communicative Intention types: Exploring, Attuning, and Resignifying, which reflect the different purposes of verbal interaction during the therapeutic conversation. Exploring includes asking for or providing new information or clarifying contents. Attuning is aimed at achieving mutual comprehension, with an important emotional component. Resignifying is focused on transforming meanings (Krause et al., 2010).

In addition, communication is expected to be determined by the role of the participant (client or therapist). For instance Stiles (1992), using the VRM, observed a different distribution for each of the participants in a therapeutic session, showing that each role has a distinctive and characteristic verbalization profile. Other studies have also shown these different role profiles (e.g., Mergenthaler, 1985, using the Therapeutic Cycles Model, and Valdés, Krause, \& Álamo, 2011, using the TACS). Different role profiles can furthermore be related to the effectiveness of the therapeutic process. The results of Hölzer, Erhard, Pokorny, Kächele, and Luborsky (1996) point in this direction, showing that in therapies with a poor outcome, therapists speak more than their clients in later phases of the treatment compared to the beginning of the therapy. Finally, comparisons of change and stuck episodes also show that it is important to address roles when studying episodes that are more or less related to change (Fernández et al., 2012).

\section{Change episodes}

To understand therapeutic conversation, it is necessary to segment the therapy into minor units because only through this fine-grained analysis can the essential nature of the mechanisms leading to clients' change be understood (Rice \& Greenberg, 1984). For this reason we analyzed the Communicative Intentions of clients and therapists specifically during change episodes, in order to characterize the kinds of Communicative Intentions that are involved in change. These episodes refer to meaningful events, moments or segments that, from the point of view of the participants or the observers of the process, seem to be associated with therapeutic change (Bastine, Fiedler, \& Kommer, 1989). These segments or moments have received various labels, such as critical events (Fitzpatrick \& Chamodraka, 2007), significant events (Elliott, 1984; Elliott \& Shapiro, 1992), task events (Rice \& Greenberg, 1984), helpful events (Elliott, 1985), and change episodes (Fiedler \& Rogge, 1989; Krause et al., 2007). The latter designation is used in this study to refer to those significant segments that stand out in the psychotherapeutic process due to the presence of a change moment (Rice \& Greenberg, 1984), a moment during which a change of meaning in the client's view of him or herself takes place. Change episodes are fragments of sessions in which there is an intensification of the process of change, culminating in a change moment (Krause et al., 2007; Reyes et al., 2008). In this view, change is regarded as the development of subjective 


\begin{tabular}{|c|c|c|c|c|c|c|c|}
\hline Therapy & Sex & Age & Outcome & Focus of therapy & $\begin{array}{c}\text { Total } \\
\text { sessions }\end{array}$ & $\begin{array}{l}\text { Change } \\
\text { episodes }\end{array}$ & $\begin{array}{l}\text { Speaking turns } \\
\text { with communi- } \\
\text { cative intentions }\end{array}$ \\
\hline Psychodynamic & $\mathrm{F}$ & 29 & Successful & $\begin{array}{l}\text { Decreasing anxiety stemming } \\
\text { from separation; strengthening } \\
\text { autonomy; expression of needs }\end{array}$ & 23 & 10 & 356 \\
\hline Psychodynamic & $\mathrm{F}$ & 41 & Successful & $\begin{array}{l}\text { Development of mourning for } \\
\text { separation and recent losses }\end{array}$ & 18 & 14 & 321 \\
\hline $\begin{array}{l}\text { Social } \\
\text { constructionist }\end{array}$ & $\mathrm{F}$ & 38 & Functional & $\begin{array}{l}\text { Resolution of conflict between } \\
\text { mother and son and between the } \\
\text { parents }\end{array}$ & 20 & 12 & 604 \\
\hline $\begin{array}{l}\text { Drug abuse } \\
\text { group therapy }\end{array}$ & $\begin{array}{l}\mathrm{M} \\
\mathrm{M} \\
\mathrm{M} \\
\mathrm{M} \\
\mathrm{M} \\
\mathrm{M}\end{array}$ & $\begin{array}{l}34 \\
29 \\
19 \\
23 \\
35 \\
49\end{array}$ & $\begin{array}{l}\text { Successful } \\
\text { Successful } \\
\text { Successful } \\
\text { Unsuccessful } \\
\text { Successful } \\
\text { Successful }\end{array}$ & $\begin{array}{l}\text { Recognition of addiction; } \\
\text { strengthening the ability to set } \\
\text { limits; identification of situations } \\
\text { of risk }\end{array}$ & 18 & 9 & 404 \\
\hline Psychodynamic & $\mathrm{F}$ & 42 & Successful & $\begin{array}{l}\text { Expression of needs; } \\
\text { strengthening autonomy; } \\
\text { increasing quality of relationships }\end{array}$ & 21 & 24 & 375 \\
\hline Total & & & & & 100 & 69 & 2060 \\
\hline
\end{tabular}

Note. Clients' age when the therapeutic process started. Outcome was measured through the Chilean version of Lambert's OQ-45.2 (de la Parra \& von Bergen, 2001; de la Parra, von Bergen, \& del Rio, 2002).

patterns of interpretation and explanation that lead to new subjective theories.

Some researchers claim that therapeutic outcome does not depend so much on isolated episodes as on their connection and evolution during the therapeutic process (Fiedler \& Rogge, 1989). Change in therapy can be gradual and linear, but also discontinuous and non-linear, although it generally shows a heterogeneous progress (Hill, 2005; Krause et al., 2007; Mergenthaler, 1998). As Hill (2005) reports, psychotherapy manifests itself in a succession of stages (exploration, insight, and action) during which therapists and clients progress from an initial impression, to the identification of therapeutic goals, and eventually to the termination of the process. Therefore, in this study, Communicative Intentions in change episodes belonging to different phases in therapy will be analysed and compared.

Considering the fact that the therapeutic process does not evolve homogeneously (Hayes, Laurenceau, Feldman, Strauss, \& Cardaciotto, 2007; Hill, 2005; Krause et al., 2007; Mergenthaler, 1998), and that this can also be observed during the therapeutic session (Bucci, 1993), one of our hypotheses states that the evolution of communication towards change may be observed not only during the process, but also during the change episode. For example, the participants' verbal communication may show differences between the change moment, the point at which the change in meanings takes place, and the initial or intermediate moments of the episode.

In brief, the aim of this study is to analyse therapists and clients' Communicative Intentions during change episodes and in different phases of therapy, in order to answer the following research questions: (1) Are there any differences between the predominant Communicative Intentions of therapists and clients? (2) Are there any differences in the Communicative Intentions predominant in the different change episode stages, and (3) in different phases of the therapeutic process?

Considering that previous studies have revealed differences in the communicative role profiles of the therapist-client dyad (Mergenthaler, 1985; Stiles, 1992; Valdés et al., 2011) and that the existing evidence regarding the TACS system illustrates its usefulness in obtaining knowledge about the evolution of communication and verbal actions related to change (Valdés et al., 2010, 2011) we hypothesize that (a) clients and therapists will use the three types of Communicative Intentions in different proportions. Following the idea that there is an evolution of therapeutic communication within sessions (Bucci, 1993) we expect to find that (b) Communicative Intentions will evolve throughout the change episode. Furthermore, we hypothesize that-since change moments are characterized by the construction of new meanings (Krause et al., 2007)-communication within change episodes will evolve in the direction of a more frequent use of Resignifying and a less frequent use of 
Exploring. Evidence regarding the heterogeneous evolution of the whole therapeutic process (Hayes et al., 2007; Hill, 2005; Krause et al., 2007) leads us to predict that (c) Communicative Intentions will evolve during the therapeutic process, showing an increase in Resignifying and a decrease in Exploring. This third hypothesis rests on theoretical and empirical literature that considers the evolution of therapeutic change as a process of successive meaning-making (Krause, 2005; Salvatore, Gelo, Gennaro, Manzo, \& Al-Radaideh, 2010). Combining hypotheses (b) and (c), we expect that (d) the pattern of the evolution of Communicative Intentions in different change episode stages and different phases of the whole therapeutic process will be a similar. By testing these hypotheses we intend to generate empirical evidence that may, as Lepper (2009, p. 1090) puts it, "enhance our clinical skills in listening for, and addressing in the here-and-now," the procedures therapists as well as clients implement during their clinical interaction.

\section{Method}

\section{Therapies and participants}

The study included 10 clients ( 4 women, 6 men; age range $=19-49$ years, $M=34.4$ years, $S D=9.13$ ) and five therapists ( 1 woman, 4 men) with 10 to 30 years of professional experience, who participated in five therapies delivered in outpatient university clinics. As the table shows, the common focuses of all therapies were interpersonal issues (Table 1). Clients participated in five brief psychotherapeutic processes of different approaches (three psychodynamic therapies, one social-constructionist, and one behavioral-oriented group therapy). The rationale of including psychotherapies of different modalities rests on the assumption that the communicative actions addressed in this research are generic, in the sense that they are present in different types of therapies.

\section{Data set}

A total of 69 separate change episodes were identified in 100 sessions belonging to five psychotherapeutic processes (see the procedure section: delimiting change episodes). The average number of change episodes per session was $0.69(S D=0.81$, range $0-4)$. The set of change episodes contained a total of 2833 speaking turns, 2060 of which met the requirements for coding a Communicative Intention (see the procedure section: coding speaking turns). The length of the episodes ranged from 3 to 139 speaking turns, with an average of $41.06(\mathrm{SD}=31.74)$.

\section{Procedure}

Written consents were signed by all clients and therapists, who agreed to be videotaped and observed through a one-way mirror by members of the research team. The research project was conducted in compliance with the review board of the Chilean National Fund for Scientific and Technological Development.

Delimiting change episodes. All psychotherapy sessions were video and audio-taped as well as observed by expert observers in situ through a one-way mirror. The observers were eight psychotherapists, all of them part of the research group, experienced in different theoretical approaches and trained in the use of a protocol developed in order to guide and facilitate the observation and recording of change moments. The raters observed the therapy processes and-independently-identified the change moments, paying attention to the client's verbalizations and non-verbal manifestations and following the indications for the identification of Change and Stuck Episodes (Fernández et al., 2012).

Raters coded a change moment when the following criteria were met: (a) theoretical correspondence: the therapeutic interaction topic agrees with the contents of one of the Generic Change Indicators, (b) verifiability: The interaction is observed in the session, (c) novelty: The specific topic of that change moment is present for the first time in the course of the therapeutic process, and (d) consistency: The change is consistent with nonverbal cues and is not denied later on in the session or in the therapy (Krause et al., 2007). These change moments were agreed on intersubjectively. When no consensus was achieved, the change moment was eliminated, and therefore not included in further analyses. This procedure prioritized consensus between raters.

Once the change moment was identified, the whole change episode was delimited, identifying its beginning according to a thematic approach. Based on transcribed sessions, raters went backwards and looked for the verbal interaction where the client and the therapist started to talk about the subject that led to the client's change. The segment of interaction between client and therapist that precedes the change moment constitutes the change episode (which ends when the change moment emerges).

Coding of speaking turns in change episodes. All delimited change episodes were broken down into speaking turns, which constituted the unit of analysis. A speaking turn is defined as "an uninterrupted utterance by one speaker, surrounded by utterances of another speaker" (Elliott, 1991, p. 99). The speaking turn included all the words uttered by the psychotherapist and the client in their turn during the psychotherapeutic dialogue (e.g., roughly a sentence of dialogue).

Speaking turns were coded using the Therapeutic Activity Coding System (TACS; Valdés et al., 2010; see Measures section). A speaking turn meets the requirements for coding a Communicative Intention if it has a subject (even if it is implicit) and a predicate. Pairs of raters coded in two consecutive stages. In the 
first one, each researcher individually coded the specific Communicative Intentions (Exploring, Attuning, and Resignifying) that appeared in the speaking turns (according to the TACS system; see below for more details). The inter-rater agreement of these individual codes is adequate $(\kappa \geq .71,95 \%$ IC $[.63, .87])$. In the second stage, the pairs of researchers discussed their differences in coding in order to obtain a fully agreed final coding (100\% agreement). These agreed categories were included in logistic regression models.

\section{Measures}

Communicative Intentions. As stated previously, a Communicative Intention refers to the purpose expressed by the speaker's words, as considered by the TACS (Krause et al., 2010). In other words, it refers to "what the participant is trying to achieve with his/her communication" (Valdés et al., 2010, p. 122), and not whether this effect is actually achieved. For example, the therapist could verbalize with the Communicative Intention of Resignifying, and it would be coded as such regardless of whether or not the client accepts the new meaning. ${ }^{1}$

According to the TACS, there are three types of Communicative Intentions: Exploring, Attuning, and Resignifying. Exploring is coded when client or therapist asks for or provides information that is unknown, or clarifies contents (e.g., the therapist asks "how would you describe your husband so that I can get an idea of him?"). Attuning is coded when the purpose is to understand or to be understood by the other; to harmonize with the other; and/or to provide feedback (e.g., the therapist says "let me see if I understand, what you are trying to say is that..." or the client expresses "I need you to understand what I am trying to explain"). Resignifying is coded when there is the purpose of generating or consolidating new meanings (e.g., the therapist says "You are telling me that you want to do something, but that you really don't dare. So I think that happens in other parts of your life and I think that it is happening here, it is happening to you right now at this very moment" (Krause et al., 2010, p. 19).

\section{Data analysis}

Logistic regression analyses were conducted to test the study's hypothesis. To perform the statistical analysis, each one of the Communicative Intentions was transformed into a dichotomous dependent variable. For example, Exploring was coded one "1" when it was used and coded zero " 0 " when Attuning or Resignifying appeared. This dichotomization process makes it possible to compare the probability of

\footnotetext{
${ }^{1}$ TACS was originally developed with data from five different psychotherapeutic approaches (psychodynamic, socialconstructionist, CBT, gestalt and humanistic).
}

occurrence of a category (coded 1) with respect to that of other categories (coded 0 ).

Three simple logistic regression equations were estimated to test the first hypothesis about the differences between therapists' and clients' Communicative Intentions. Each of the dichotomized Communicative Intentions was regressed on the Actor variable (Clients $=1$ and Therapist $=0$ as reference category).

A similar procedure was used to test the second hypothesis, comparing the probability of occurrence for Communicative Intention types through the change episode stages. Change episodes were divided into five stages (henceforth, the variable will be referred to as change episode stage). The final change episode stage was composed of the last six speaking turns, in order to include the "change moment" in this stage. When the remaining speaking turns were more than 15, the initial change episode stage was formed by the first six speaking turns, so as to homogenize the number of speaking turns belonging to the initial and final change episode stages; however, if the remaining speaking turns were between 10 and 15 , the initial change episode stage was formed by five or fewer Communicative Intentions, depending on the length of each episode. After defining the initial and the final change episode stages, the remaining speaking turns were divided into three equal parts, coding only the middle section as the "middle change episode stage." The other two parts of the middle stage were considered transitional stages and were not included in the analysis. Each of the dichotomized Communicative Intentions was regressed on change episode stage. Change episode stage was included as a categorical variable comparing the initial and the middle stages vs. the final stage (final stage as reference category).

Simple logistic regression equations were estimated to test the third hypothesis, comparing the probability of occurrence of Communicative Intention types through the phase of the therapy. The therapy phase variable was constructed by dividing the total number of sessions into three equal parts, so that the beginning, middle and final phases would have a similar number of sessions. For example, in a therapeutic process of 18 sessions, each phase will have 6 sessions (the number of sessions per therapeutic process is shown in Table 1). Therapy phase was included as a categorical variable comparing the first and second phases vs. the third phase (third phase as reference category).

To test the last hypothesis two multiple logistic regression analyses were carried out. These analyses show the variations of Communicative Intentions in the different change episode stages and the phases of the therapeutic process, and reveal any differences between the Communicative Intentions of clients and therapists in both types of evolution. To perform these statistical analysis two independent logistic regression equations were estimated: 


$$
\begin{aligned}
& \text { (a) Logit }(y)=\mathrm{a}_{\text {Constant }}+\mathrm{b} 1_{\text {Actor }}+\mathrm{b} 2_{\text {Stage }(\mathrm{I} / \mathrm{F})}+\mathrm{b} 3_{\text {Stage }(\mathrm{I} / \mathrm{F})} \\
& +\left[\mathrm{b} 4_{\text {Actor }} \text { Stage }(\mathrm{I} / \mathrm{F})\right]+\left[\mathrm{b} 5_{\text {Actor }} \text { Stage }(\mathrm{I} / \mathrm{F})\right] \\
& \text { (b) Logit }(y)=\mathrm{a}_{\text {Constant }}+\mathrm{b} 1_{\text {Actor }}+\mathrm{b} 2_{\text {Phase }(1 / 3)}+\mathrm{b} 33_{\text {Phase }(1 / 3)} \\
& +\left[\mathrm{b} 4_{\text {Actor }} \text { Phase }(1 / 3)\right]+\left[\mathrm{b} 5_{\text {Actor* }}^{* \text { Phase }(2 / 3)]}\right.
\end{aligned}
$$

The main effects of each of the predictors: Actors, change episode stages or phases of the therapeutic process were included first in the logistic regression equation. Afterwards, interaction terms were added to the model.

Logistic regression results are presented following the recommendations by Peng, Lee, and Ingersoll (2002). Tables displaying main effects parameters are presented for all the variables analysed. The interaction term is incorporated only when it is statistically significant. Odds ratios were estimated to show interaction terms with the simplest model of predictors. No relevant differences exist between the simple and the complete models.

\section{Results}

Considering both clients' and therapists' speech conjointly $(N=2060)$, the most frequent Communicative Intention is Exploring (45.2\%). Resignifying comes second with $39.4 \%$, while Attuning reaches $15.4 \%$.

\section{Clients and therapists Communicative Intentions}

As was hypothesized, clients and therapists differ regarding their use of the three Communicative Intentions (see Figure 1). Statistically significant differences can be observed in the probability of occurrence of the Communicative Intentions in client and therapist speech. Therapists attune $(\beta=-.96, \mathrm{OR}=$ $.39, p<.001,95 \%$ CI $[.30, .50])$ and resignify $(\beta=$ -.38 , OR $=.68, p<.001,95 \%$ CI $[.57, .82]$ ) more often than clients; in contrast, the latter tend to explore more frequently $(\beta=.84, \mathrm{OR}=2.31, p<.001,95 \%$ CI $[1.93,2.76])$.

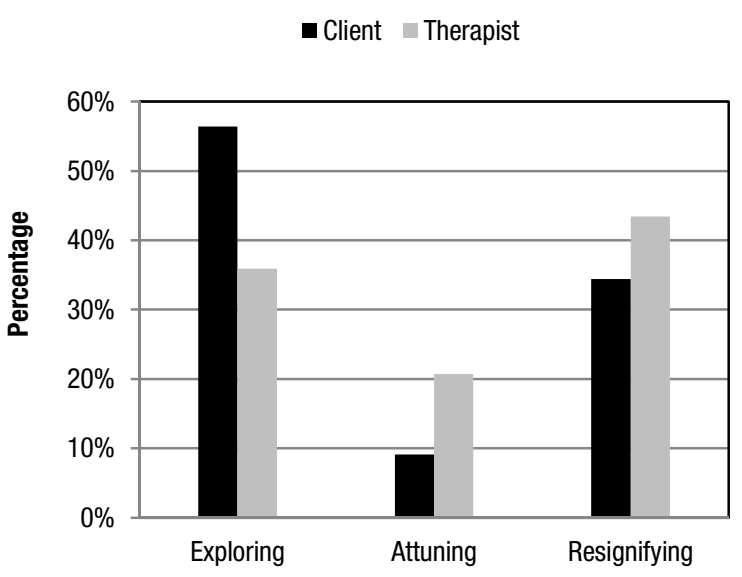

Figure 1. Client and therapist use of the different communicative intentions.

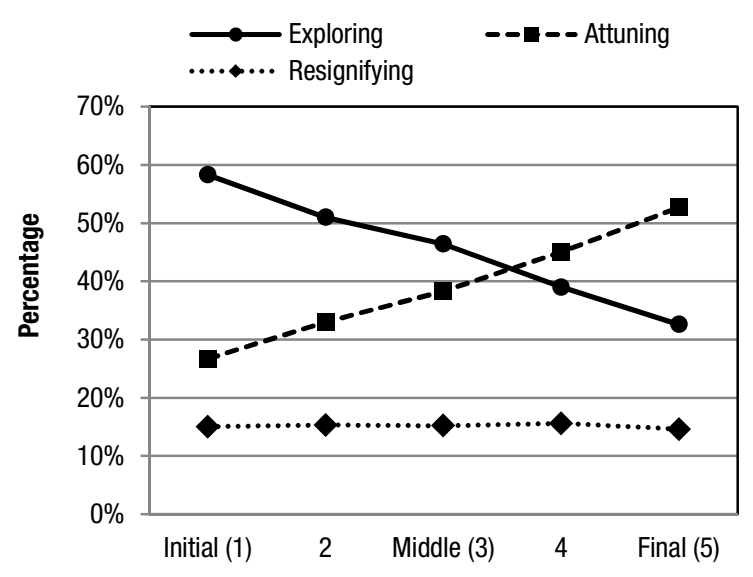

Figure 2. Communicative intentions at different change episode stages.

\section{Communicative Intentions through the change episode (change episode stages)}

Figure 2 shows the use of the Communicative Intentions by both participants of the therapeutic dialog throughout the different change episode stages. The results indicate that the probability of Exploring is higher in the initial $(\beta=1.06, \mathrm{OR}=2.88, p<.001$, $95 \% \mathrm{CI}[2.18,3.82])$ and middle stages $(\beta=.58$, OR $=1.79, p<.001,95 \%$ CI $[1.36,2.35])$ compared to the final stage of the change episode. The opposite pattern was observed in the case of Resignifying: The probability of Resignifying is lower in the initial $(\beta=$ $-1.12, \mathrm{OR}=.33, p<.001,95 \% \mathrm{CI}[.26, .44])$ and middle stages $(\beta=-.58, \mathrm{OR}=.56, p<.001,95 \% \mathrm{CI}$ $[.42, .73])$ compared to the final change episode stage. The use of Attuning remains constant in the three change episode stages $\left(\right.$ Model $\chi^{2}(2, N=1266)=$ $.07, p=.97, \&-2 L L=1067.11)$. These results are consistent with the second hypothesis: Since change moments are characterized by the construction of new meanings, communication within change episodes will evolve in the direction of a more frequent use of Resignifying and a less frequent use of Exploring.

\section{Communicative Intentions throughout the ther- apeutic process (phases of therapy)}

Communicative intentions were used differentially according to the phase of the therapeutic process by the participants in the therapeutic dialog (see Figure 3). Statistically significant differences were observed in the probability of occurrence of Exploring and Attuning, but not in the probability of Resignifying $\left(\right.$ Model $\chi^{2}(2, N=2060)=2.25, p=.32, \&-2 \mathrm{LL}=$ 2759.67).

Compared with the final phase (third phase of therapy), the probability of Exploring is higher both in the initial $(\beta=.36, \mathrm{OR}=1.43, p<.001,95 \%$ CI $[1.15$, 1.79]) and middle phases of therapy $(\beta=.32$, OR $=$ $1.37, p<.05,95 \%$ CI $[1.09,1.72])$. Additionally, in the 


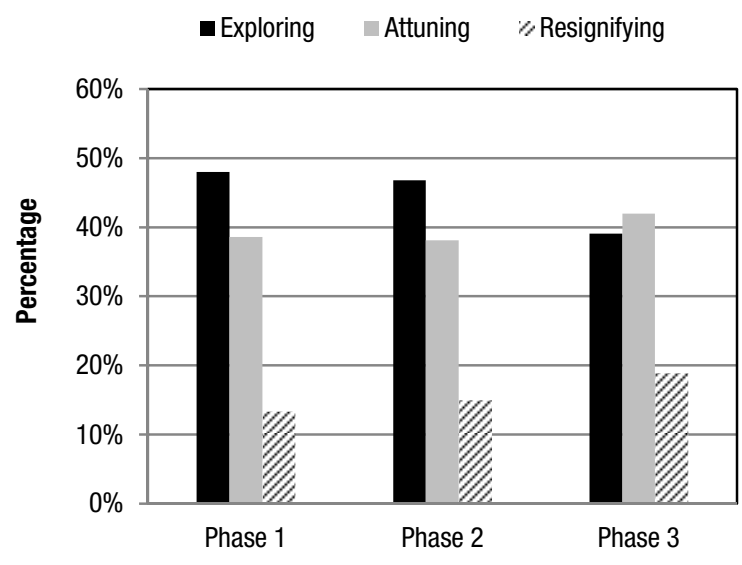

Figure 3. Use of communicative intentions at different stages of therapy.

third therapy phase there was a more extensive use of Attuning than in the first phase $(\beta=-.41, \mathrm{OR}=.67, p$ $<.01,95 \%$ CI $[.50, .90])$, but no differences were observed when comparing the second and third phases $(\beta=-.27, \mathrm{OR}=.76, p=.71,95 \% \mathrm{CI}[.57,1.02])$.

These results partially support the third hypothesis. Although a decrease in Exploring was observed, there was no evidence of an increase in Resignifying as the therapy process progressed.

\section{Evolution of client and therapist Communicative Intentions in change episode stages and therapy phases}

The final hypothesis stipulates that the pattern of the evolution of Communicative Intentions in different change episode stages and therapeutic phases will be similar. Given the results showing the differences between clients and therapists, this hypothesis must be tested considering the speakers of the therapeutic discourse and the micro (change episode stages) and macro (therapy process phases) moments of the therapeutic process jointly.

Change episode stages. In order to analyse the effect of the change episode stages on the probability of using Communicative Intentions (Exploring, Attuning and Resignifying), each of dichotomized dependent variables was regressed on the variables actors, change episode stages and their interaction.

As Table 2 shows, the relation between the change episode stage and the probability of Exploring and Resignifying depends on who the speaker is (significant interaction terms). There were no significant interactions between actor and change episode stages when predicting Attuning. ${ }^{2}$

Odds ratios were estimated to account for the in-

\footnotetext{
${ }^{2}$ Direct effects are not interpreted when interactions are present.
}

teraction terms (Actor $\mathrm{X}$ Change episode stage). When the odds ratio is equal to 1 , both categories have the same odds. When the odds ratio is greater than 1 , the odds for one of the categories of variables (i.e., the clients) are greater than the odds for the reference category (i.e., the therapist). When the odds ratio is less than 1 , the reverse is true (Hosmer $\&$ Lemeshow, 2000).

The results indicate that clients were 3.7 times more likely to use Exploring than therapists in the initial change episode stage $(\mathrm{OR}=3.72,95 \%$ IC $[2.40,5.75])$. This pattern was less clear at the end of the change episode (final stage), where clients Explored only one and a half times more than therapists (OR $=1.69,95 \%$ IC $[1.13,2.54])$.

With respect to Resignifying, the odds ratios indicate that clients were less likely to resignify than therapists in the initial (OR $=.43,95 \%$ IC $[.26, .68])$, and middle change episode stages $(\mathrm{OR}=.67,95 \%$ IC $[.45, .99])$, although this difference was less clear in the final stage, when clients and therapists had the same probability of Resignifying ( $\mathrm{OR}=1.17,95 \%$ IC $[.81,1.71])$.

In brief, the relation between the change episode stage and the probability of Exploring depends on who the speaker is. In the initial change episode stage the clients explore much more frequently than therapists (3 times more frequently); in contrast, this Communicative Intentions asymmetry decreases in the final change episode stage. Additionally, something similar occurs with Resignifying. Communication asymmetry, present in the initial and middle change episode stages and characterized by a higher Resignifying rate by the therapist compared with the client, disappears in the final change episode stage.

Phases of the therapeutic process. In order to analyse the effect of the phases of the therapeutic process on the probability of using each of the Communicative Intentions, each of the dichotomized dependent variables was regressed on the variables actors, therapy phase, and their interaction.

As Table 3 shows, the relation between phases of therapy and the probability of Exploring, Attuning and Resignifying depends on who the speaker is (significant interaction terms).

Odds ratios indicate that clients are more likely to explore than therapists in the first $(\mathrm{OR}=2.99,95 \%$ IC $[2.22,4.02])$ and second phases (OR $=2.69,95 \%$ IC $[1.99,3.64])$ compared to the third therapy phase. At the end of the therapy (third phase), this pattern is less clear; as the use of Exploring by clients and therapists becomes more similar (OR $=1.46,95 \%$ IC $[1.03,2.05])$.

With respect to Attuning, odds ratios indicate that clients were less likely to use Attuning than therapists in the first therapy phase (OR $=.22,95 \%$ IC $[.12$, .38]) compared to the third therapy phase. In the last therapy phase, clients increased their tendency to Attune, thus establishing a less asymmetric pattern in 
Table 2. Logistic regression models predicting therapist-client communicative intentions during change episodes

\begin{tabular}{|c|c|c|c|c|c|}
\hline \multirow[b]{2}{*}{ Model } & \multirow[b]{2}{*}{$\beta$} & \multirow[b]{2}{*}{$S E \beta$} & \multirow[b]{2}{*}{ OR } & \multicolumn{2}{|c|}{$95 \% \mathrm{CI}$} \\
\hline & & & & Low & High \\
\hline \multicolumn{6}{|l|}{ Exploring } \\
\hline Actor $^{\mathrm{a}}$ & $.68^{* * *}$ & .14 & 1.98 & 1.49 & 2.63 \\
\hline Initial change episode stage $\mathrm{e}^{\mathrm{b}}$ & $.93^{* * *}$ & .19 & 2.56 & 1.78 & 3.67 \\
\hline Middle change episode stage ${ }^{b}$ & $.65^{* * *}$ & .14 & 1.91 & 1.44 & 2.53 \\
\hline Actor $\mathrm{x}$ Stage (Initial vs Final) ${ }^{\mathrm{c}}$ & $.63^{*}$ & .26 & 1.88 & 1.15 & 3.16 \\
\hline Actor $\mathrm{x}$ Stage (Middle $v s$ Final) ${ }^{\mathrm{c}}$ & - & - & & & \\
\hline Constant & $-1.10^{* * *}$ & .13 & & & \\
\hline \multicolumn{6}{|l|}{ Attuning } \\
\hline Actor $^{\mathrm{a}}$ & $-1.19^{* * *}$ & .18 & .31 & .21 & .44 \\
\hline Initial change episode stage ${ }^{\mathrm{b}}$ & -.09 & .20 & .92 & .62 & 1.35 \\
\hline Middle change episode stage ${ }^{b}$ & -.03 & .20 & .98 & .66 & 1.43 \\
\hline Actor $\mathrm{x}$ Stage (Initial vs Final) ${ }^{c}$ & - & - & & & \\
\hline Actor $\mathrm{x}$ Stage (Middle $v$ s Final) ${ }^{\mathrm{c}}$ & - & - & & & \\
\hline Constant & $-1.28^{* * *}$ & .15 & & & \\
\hline \multicolumn{6}{|l|}{ Resignifying } \\
\hline Actor ${ }^{\mathrm{a}}$ & .16 & .19 & 1.17 & .81 & 1.71 \\
\hline Initial change episode stage $\mathrm{e}^{\mathrm{b}}$ & $-.73^{* * *}$ & .19 & .48 & .33 & .71 \\
\hline Middle change episode stage ${ }^{b}$ & -.33 & .19 & .72 & .49 & 1.05 \\
\hline Actor $\mathrm{x}$ Stage (Initial vs Final) ${ }^{\mathrm{c}}$ & $-1.02^{* * *}$ & .31 & .36 & .20 & .67 \\
\hline Actor $\mathrm{x}$ Stage (Middle $v s$ Final) ${ }^{\mathrm{c}}$ & $-.56^{*}$ & .28 & .57 & .33 & .99 \\
\hline Constant & .03 & .14 & & & \\
\hline
\end{tabular}

Note. Model based on $N=1266$ speaking turns. 95\% CI: 95\% Confidence Interval. Overall model evaluation for Exploring: $\chi^{2}(4 d f)=117.80, p<.001 \&-2 L L=1626.96$; Overall model evaluation for Attuning: $\chi^{2}(3)=47.92, p<.001 \&-2 L L=$ 1019.25; Overall model evaluation for Resignifying $\chi^{2}(5)=78.56, p<.001 \&-2 L L 1621.03$.

${ }^{a}$ Reference category $0=$ Therapist. $^{b}$ Reference category $0=$ Final Change episode stage.

${ }^{*} p<.05 ;{ }^{* *} p<.01$; $^{* * *} p<.001$.

the use of this Communicative Intention $(\mathrm{OR}=0.60$, 95\% IC [.39, .94]).

Regarding Resignifying, the results indicate that clients were less likely to use this Communicative Intention in the first phase of the therapy, compared to the third phase $(\mathrm{OR}=.58,95 \%$ IC $[.43, .78])$. In the final phase of therapy, the differences in the use of Resignifying by clients and therapists disappear (OR $=.94,95 \% \mathrm{IC}[.67,1.32])$.

In summary, the relation between the therapy phase and the probability of Exploring depends on who the speaker is. In the first therapeutic phases, clients explore much more often than therapists (nearly 3 times more often), but this asymmetry decreases in the final therapy phase. There is also less asymmetry between clients and therapists in their use of Attuning in the final phase of therapy. Finally, client-therapist asymmetry in the first therapeutic phase, characterized by the more frequent use of Resignifying by therapists, disappears in the third therapy phase.

These results support the hypothesis of a parallelism between the micro (change episode stages) and macro (whole therapy) process. Similar patterns were observed at both levels (micro vs. macro) regarding the participants' use of Exploring and Resignifying.

\section{Discussion}

We have described the heterogeneity of the therapeutic process through the implementation and results of a micro-analytical research focused on the analysis of the Communicative Intentions performed during change episodes. With an emphasis on the real actions of clients and therapists, our study intended to bring research and practice closer, an objective shared by many scholars in the history of psychotherapy research (Goldfried, Raue, \& Castonguay, 1998; Marmar, 1990; Stiles, Shapiro, \& Fith-Cozens, 1990).

Our results show that, in general, some Communicative Intentions are performed more often than others; the most frequent one is Exploring, followed by Resignifying and Attuning.

When looking at client and therapist verbalizations, different communicative profiles where found, as had been hypothesized. Specifically, therapists tend to attune and resignify more than clients, while the latter 
Table 3. Logistic regression models predicting therapist-client communicative intentions during therapy phases.

\begin{tabular}{|c|c|c|c|c|c|}
\hline \multirow[b]{2}{*}{ Model } & \multirow[b]{2}{*}{$\beta$} & \multirow[b]{2}{*}{$S E \beta$} & \multirow[b]{2}{*}{ OR } & \multicolumn{2}{|c|}{$95 \% \mathrm{CI}$} \\
\hline & & & & Low & High \\
\hline \multicolumn{6}{|l|}{ Exploring } \\
\hline Actor $^{\mathrm{a}}$ & $.38^{*}$ & .17 & 1.46 & 1.04 & 2.05 \\
\hline First phase $\mathrm{b}^{\mathrm{b}}$ & .11 & .15 & 1.11 & .83 & 1.51 \\
\hline Second phase $\mathrm{b}^{\mathrm{b}}$ & -.02 & .16 & .98 & .71 & 1.35 \\
\hline Actor $\mathrm{x}$ Phase (1 vs 2) & $.72^{* *}$ & .23 & 2.05 & 1.30 & 3.22 \\
\hline Actor $\mathrm{x}$ Phase (2 vs 3) & $.61^{* *}$ & .23 & 1.85 & 1.17 & 2.91 \\
\hline Constant & $-.62^{* * *}$ & .12 & & & \\
\hline \multicolumn{6}{|l|}{ Attuning } \\
\hline Actor $^{\mathrm{a}}$ & $-.78^{* * *}$ & .16 & .46 & .34 & .62 \\
\hline First phase ${ }^{b}$ & -.31 & .17 & .74 & .53 & 1.02 \\
\hline Second phase $\mathrm{e}^{\mathrm{b}}$ & -.24 & .15 & .78 & .58 & 1.06 \\
\hline Actor $\mathrm{x}$ Phase (1 vs 2) & $-.74^{*}$ & .33 & .48 & .25 & .91 \\
\hline Actor $\mathrm{x}$ Phase (2 vs 3) & - & - & & & \\
\hline Constant & $-1.15^{* * *}$ & .12 & & & \\
\hline \multicolumn{6}{|l|}{ Resignifying } \\
\hline Actor $^{\mathrm{a}}$ & -.06 & .17 & .94 & .67 & 1.32 \\
\hline First phase ${ }^{b}$ & .04 & .15 & 1.04 & .77 & 1.39 \\
\hline Second phase $\mathrm{b}^{\mathrm{b}}$ & .05 & .16 & 1.05 & .77 & 1.44 \\
\hline Actor $\mathrm{x}$ Phase (1 vs 2) & $-.48^{*}$ & .23 & .62 & .39 & .97 \\
\hline Actor $\mathrm{x}$ Phase (2 vs 3) & -.43 & .23 & .65 & .42 & 1.03 \\
\hline Constant & -.30 & .12 & & & \\
\hline
\end{tabular}

Note. Model based on $N=2060$ speaking turns. 95\% CI: 95\% Confidence Interval. Overall model evaluation for Exploring: $\chi^{2}(5)=112.76, p<.001 \&-2 L L=2723.94$; Overall model evaluation for Attuning: $\chi^{2}(4)=69.58, p<.001 \&-2 L L=1702.90$; Overall model evaluation for Resignifying $\chi^{2}(3)=19.83, p<.001 \&-2 L L 2742.09$.

${ }^{a}$ Reference category $0=$ Therapist. ${ }^{\mathrm{b}}$ Reference category $0=$ Third therapy phase.

${ }^{*} p<.05 .{ }^{* *} p<.01{ }^{* * *} p<.001$.

explore more. The fact that both actors have different profiles in their use of Communicative Intentions can be understood as an indicator of the complementary nature of verbal interaction during therapeutic dialogue (Heatherington, 1988). These results enrich those observed in other studies showing the difference in clients' and therapists' communication profiles (e.g., Hölzer et al., 1996; Stiles, 1992; Valdés et al., 2011).

With regard to the hypothesis that Communicative Intentions will evolve during the change episode, the results show that Exploring is more frequent during the initial change episode stage while Resignifying is more frequent in the final episode stage, and that this evolution depends mostly on the client. This result is concordant with the clinical impression that every process requires an initial stage of inquiry or information exchange: In order to understand or be understood, clarification is sought and attention is directed to certain key points, especially by the client (as the TACS system states [Krause et al., 2010] the
Intention Exploring includes communicative actions aimed at clarifying). The result supports the idea that the construction of new meanings is an interactive activity where both participants work together delivering or asking for material and then working on a new meaning (Anderson, 1997). This implies that client and therapist, by means of their differential use of Communicative Intentions, configure a context in which the client can be the main agent of his/her subjective changes (Reyes et al., 2008).

The low but constant presence of Attuning throughout the entire episode can be interpreted as evidence of the need for a shared meaning context between client and therapist. The verbalizations involving Attuning refer to a core "ingredient" of the psychotherapy process, the therapeutic alliance, specifically to the positive bond that is one of the main dimensions of the construct (Krause, Altimir, \& Horvath, 2011). This important aspect of the therapeutic process directly contributes to overall client 
change across a range of theoretically diverse treatments (Horvath, Del Re, Flückiger, \& Symonds, 2011; Horvath \& Symonds, 1991; Martin, Garske, \& Davis, 2000), and can be defined as the dynamic interpersonal process where verbalizations allude to therapist empathy, degree of client involvement in treatment, being understood, etc. (Horvath \& Greenberg, 1994; Krause et al., 2011). All of these elements can be found under the concept of Attuning, which refers to communicative and emotional adjustment (understanding or being understood by the other, achieving a harmonious relationship, and dealing with feedback issues). Therefore, having a constant presence of Attuning is regarded as a fundamental requisite for change, allowing the construction of new meanings and thus of subjective change (Krause, 1992).

On the other hand, as was hypothesized, the results of the analysis of Communicative Intentions throughout the therapeutic process show that verbal communication can distinguish between phases, thus providing evidence for the notion that therapy evolves (Hill, 2005; Krause et al., 2007), with clients and therapists going through different types of communication.

When considering discourse of clients and therapists jointly, the initial and middle phases of the process have a similar pattern, in which Exploring predominates over Attuning and Resignifying. This pattern changes in the final phase of therapy, where Exploring is less frequent and Attuning increases compared to the first.

In contrast, when their discourse is separated by speaker, the clients' increased use of Resignifying at the end of the process becomes apparent. This result can be understood from a clinical point of view, as clients tend to need less of the therapist's interpretations when they acquire a certain degree of autonomy in the construction of their own subjective theories (Krause, $2005,2011)$. On the other hand, the more frequent use of Attuning can be related to the fact that when termination comes, especially in brief psychotherapies (like the ones studied), there is a need to evaluate the process, provide feedback, check the work done, assess progress, etc.

The results of this study show that the therapeutic process-at least when the focus is on verbal clienttherapist communication-is not homogeneous (e.g., Mergenthaler, 1998), either in terms of its global evolution or its microprocess. Even small therapy segments display such heterogeneity. These results go beyond the existing literature, allowing the development of a model that facilitates understanding of the complexities of the therapeutic process by simultaneously including a macro level (session to session) and a micro level (within session) approach.

In general terms, a parallelism is observed between the evolution of change episodes and the global evolution of therapeutic phases. Considering these results, this model has a hologramatic characteristic, in the sense that the features observed at the macro level (e.g., the evolution of Communicative Intentions throughout the psychotherapy) are also observed at the micro level (e.g., the evolution of Communicative Intentions within change episodes). This characteristic has implications not only for ongoing and future research, but also for clinical practice.

With respect to clinical practice, these results might encourage therapists to attend to their own and the client's verbalizations, since they show that therapists should allow and even encourage clients to explore initially, not forgetting to resignify what is said during the conversation, while constantly attuning with the client. This general strategy does not have to be used only within sessions (micro level): Therapists could also consider the phases of the therapeutic process (macro lev$\mathrm{el}$ ), allowing the client to increasingly resignify during the whole process so he/she can gain autonomy in the construction of his/her subjective change.

With respect to future directions of research, the results of this study suggest linking Communicative Intentions to the evolution of change-through the use of Generic Change Indicators (Krause et al., 2007), in order to evaluate how the verbalizations of the actors lead to different types of change-and different outcomes, comparing successful and unsuccessful therapies. Furthermore, it would be important to deepen the analysis of the relation between Communicative Intentions and the construction of the therapeutic alliance. An example of this would be to study the use of Attuning as part of the construction of a positive bond by relating its use to measurements of therapeutic alliance like the Working Alliance Inventory (WAI; Horvath \& Greenberg, 1986).

A limitation of this study is the fact that the cases included in the study, since they come from natural settings, do not have formal DSM-IV diagnosis. Therefore, a challenging research topic for the future would be to relate the evolution of Communicative Intentions to different client profiles; for example, looking at a specific disorder, such as depression, or even more ambitiously, at personality disorders.

\section{Acknowledgement}

This research was supported by the Chilean National Fund for Scientific and Technological Development, Projects No 1060768 and No 1080136 and the Chilean Millennium Scientific Initiative, Project $\mathrm{Nr}$. NS100018.

\section{References}

Anderson, R. H. (1997). Conversation, language, and possibilities: A postmodern approach to therapy. New York: Basic Books.

Bastine, R., Fiedler, P., \& Kommer, D. (1989). Was ist therapeutisch an der Psychotherapie? [What is therapeutic about psychotherapy?]. Zeitschrift für klinische Psychologie und Psychotherapie, 18(1), 3-22.

Bucci, W. (1993). The development of emotional meaning in free association: A multiple code theory. In A. Wilson, \& J. 
E. Gedo (Eds.), Hierarchical concepts in psychoanalysis (pp. 3-47). New York: Guilford Press.

de la Parra, G., \& von Bergen, A. (2001, June). Administration of the Outcome Questionnaire OQ-45.2 in Santiago de Chile: Validity, reliability, applicability, normative data and clinical projections. Paper presented at the 32nd International Congress of the Society for Psychotherapy Research, Montevideo, Uruguay.

de la Parra, G., von Bergen, A., \& del Rio, M. (2002). Primeros Hallazgos de la aplicación de un instrumento que mide resultados psicoterapéuticos en una muestra de pacientes y de poblacion general [Preliminary findings of the application of an instrument that measures psychotherapeutic results in a sample of patients and general population]. Revista Chilena de Neuropsiquiatría, 40, 201-209.

Detert, N., Llewelyn, S., Hardy, G., Barkham, M., \& Stiles, W. (2006) Assimilation in good-and poor-outcome cases of very brief psychotherapy for mild depression: An initial comparison. Psychotherapy Research, 16(4), 393-407. doi: $10.1080 / 10503300500294728$

Elkin, L., Parloff, J. M., Hadley, S. W., \& Autrey, J. H. (1985). NIMH treatment of depression collaborative research program. Archives of General Psychiatry, 42, 305-316. doi:10.1001/archpsyc. 1985.01790260103013

Elliott, R. (1984). A discovery-oriented approach to significant change events in psychotherapy: Interpersonal process recall and comprehensive process analysis. In L. Rice \& L. S. Greenberg (Eds.), Patterns of change: intensive analysis of psychotherapy process (pp. 249-286). New York: Guilford.

Elliott, R. (1985). Helpful and nonhelpful events in brief counseling interviews: An empirical taxonomy. Journal of Counseling Psychology, 32(3), 307-322. doi: 10.1037/00220167.32.3.307

Elliott, R. (1991). Five dimensions of therapy process. Psychotherapy Research, 1,92-103. doi: 10.1080/ 10503309112331335521

Elliott, R., \& Shapiro, D. A. (1992). Client and therapist as analysts of significant events. In S. G. Toukmanien \& D. L. Rennie (Eds.), Psychotherapy process research: Paradigmatic and normative approaches (pp. 163-186). Newbury Park, CA: Sage.

Evans, M. D., Piasecki, J. M., Kriss, M. R., \& Hollon, S. D. (1984). Raters' manual for the Collaborative Study Psychotherapy Rating Scale-Form 6. Minneapolis: MN University of Minnesota and the St. Paul-Ramsey Medical Center.

Fernández, O., Herrera, P., Krause, M., Pérez, J. C., Valdés, N., Vilches, O., \& Tomicic, A. (2012). Episodios de Cambio y Estancamiento en Psicoterapia: Características de la comunicación verbal entre pacientes y terapeutas. [Change and Stuck Episodes in Psychotherapy: Characteristics of Verbal Communication between Patients and Therapists]. Terapia Psicológica, 30(2), 5-22. doi: 10.4067/S071848082012000200001

Fiedler, P., \& Rogge, K. E. (1989). Zur Prozeßuntersuchung psychotherapeutischer Episoden. Ausgewählte Beispiele und Perspektiven. [Towards process research of psychotherapeutic episodes. Selected examples and perspectives]. Zeitschrift für Klinische Psychologie und Psychotherapie,, 18, 45-54.

Fitzpatrick, M. R., \& Chamodraka, M. (2007). Participant critical events: a method for identifying and isolating significant therapeutic incidents. Psychotherapy Research, 17, 622-627. doi: 10.1080/10503300601065514.

Gabalda, I. C. (2006). The assimilation of problematic experiences in linguistic therapy of evaluation: How did María assimilate the experience of dizziness?. Psychotherapy Research, 16, 422-435. doi: 10.1080/10503300600756436.

Goldberg, D. P., Hobson, R. F., Maguire, G. P., Margison, F. R., O'Dowd, T., Osborn, M., \& Moss, S.. (1984). The clarification and assessment of a method of psychotherapy. British Journal of Psychiatry, 144, 567-575. doi: 10.1192/bjp.144.6.567

Goldfried, M. R., Raue, P. J., \& Castonguay, L. G. (1998). The therapeutic focus in significant sessions of master therapists: A comparison of cognitive-behavioral and psychodynamicinterpersonal interventions. Journal of Consulting and Clinical Psychology, 66(5), 803-810. doi: 10.1037/0022006X.66.5.803

Hayes, A. M., Laurenceau, J.-P., Feldman, G., Strauss, J. L., \& Cardaciotto, L. (2007). Change is not always linear: The study of nonlinear and discontinuous patterns of change in psychotherapy. Clinical Psychology Review, 27(6), 715-723. doi:10.1016/j.cpr.2007.01.008

Heatherington, L. (1988). Coding relational communication control in counseling: Criterion validity. Journal of Counseling Psychology, 35(1), 41-46. doi: 10.1037/00220167.35.1.41

Hill, C. E. (1978). Development of a system for classifying counselor responses. Journal of Counseling Psychology, 25, 461-468. doi: 10.1037/0022-0167.25.5.461

Hill, C. E. (2005). Therapist techniques, client involvement, and the therapeutic relationship: inextricably intertwined in the therapy process. Psychotherapy: Theory, Research, Practice, Training, 42(4), 431-442. doi: 10.1037/00333204.42.4.431

Hölzer, M., Erhard, M., Pokorny, D., Kächele, H., \& Luborsky, L. (1996). Vocabulary measures for the evaluation of therapy outcome: Re-studying transcripts from the Penn Psychotherapy Project. Psychotherapy Research, 6(2), 95-108. doi: $10.1080 / 10503309612331331618$

Horvath, A. O., Del Re, A. C., Flückiger, C., \& Symonds, D. (2011). The alliance in adult psychotherapy. Psychotherapy: Theory, Research, Practice, Training, 48(1), 9-16. doi: $10.1037 / \mathrm{a} 0022186$

Horvath, A. O., \& Greenberg, L. S. (1986). The development of the Working Alliance Inventory. In L. Greenberg \& W. Pinsof (Eds.), The psychotherapeutic process: $A$ research handbook (pp. 529-556). New York: Guilford Press.

Horvath, A. O., \& Greenberg, L. S. (1994). Introduction. In A. O. Horvath \& L. S. Greenberg (Eds.), The working alliance: Theory, research, and practice. New York: Wiley.

Horvath, A. O., \& Symonds, B. D. (1991). Relation between working alliance and outcome in psychotherapy: A metaanalysis. Journal of Counseling Psychology, 38(2), 139-149. doi: 10.1037/0022-0167.38.2.139

Hosmer, D. W., \& Lemeshow, S. (2000). Applied logistic regression (2nd ed.). New York: Wiley.

Krause, M. (1992). Efectos subjetivos de la ayuda psicológica: Discusión teórica y presentación de un estudio empírico [Subjective effects of psychologycal help: Theoric discusión and presentation o an empiric study]. Psykhe, 1 , 41-52. Retrieved from http://www.psykhe.cl/index.php/ psykhe/article/view/15

Krause, M. (2005). Psicoterapia y Cambio. Una Mirada desde la Subjetividad. [Psychotherapy and Change. A View from Subjetivity] (1st ed.). Santiago de Chile: Ediciones Universidad Católica.

Krause, M. (2011). Psicoterapia y Cambio. Una Mirada desde la Subjetividad. [Psychotherapy and Change. A View from Subjetivity] (2nd ed.). Santiago de Chile: Ediciones Universidad Católica.

Krause, M., Altimir, C., \& Horvath, A. (2011). Deconstructing the therapeutic alliance: Reflections on the underlying dimensions of the concept. Clinica y Salud, 22(3), 267-283.

Krause, M., Valdés, N., \& Tomicic, A. (2010). Therapeutic Activity Coding System (TACS-1.0). Psychotherapy and Change Chilean Research Program. Retrieved from: http://www.psychotherapyandchange.org

Krause, M., de la Parra, G., Arístegui, R., Dagnino, P., Tomicic, A., Valdés, N., ... \& Ben-Dov, P. (2007). The evo- 
lution of therapeutic change studied through generic change indicators. Psychotherapy Research, 17(6), 673-689. doi: $10.1080 / 10503300601158814$

Lepper, G. (2009). The pragmatics of therapeutic interaction: An empirical study. International Journal of Psychoanalysis, 90(5), 1075-1094. doi:10.1111/j.1745-8315.2009.00191

Mahrer, A. R., Nadler, W. P., Stalikas, A., Schachter, H. M., \& Sterner, I. (1988). Common and distinctive therapeutic change processes in client-centered, rational-emotive, and experiential psychotherapies. Psychological Reports, 62(3), 972-974. doi: 10.2466/pr0.1988.62.3.972

Marmar, C. R. (1990). Psychotherapy process research: Progress, dilemmas, and future directions. Journal of Consulting and Clinical Psychology, 58(3), 265-272. doi: 10.1037/0022-006X.58.3.265

Martin, D. J., Garske, J. P., \& Davis, M. K. (2000). Relation of the therapeutic alliance with outcome and other variables: A meta-analytic review. Journal of Consulting and Clinical Psychology, 68(3), 438-450. doi: 10.1037/0022-006X.68.3.438

Mergenthaler, E. (1985). Textbank systems. Computer science applied in the field of psychoanalysis. Heidelberg: Springer.

Mergenthaler, E. (1998). Cycles of emotion-abstraction patterns: A way of practice oriented process research? The British Psychological Society, Psychotherapy Section Newsletter, 24, 16-29.

Peng, C-Y. J., Lee, K. L., \& Ingersoll, G. M. (2002). An introduction to logistic regression analysis and reporting. The Journal of Educational Research, 96(1), 3-14. doi: 10.1080/00220670209598786

Reyes, L., Arístegui, R., Krause, M., Strasser, K., Tomicic, A., Valdés, N., ... \& Ben-Dov, P. (2008). Language and therapeutic change: A speech acts analysis. Psychotherapy Research, 18, 8-13. doi:10.1080/10503300701576360

Rice, L., \& Greenberg, L. (1984). Patterns of change. New York: Guilford.

Salvatore, S., Gelo, O., Gennaro, A., Manzo, S., \& AlRadaideh, A. (2010). Looking at psychotherapy as an intersubjective dynamic of sensemaking. A case study with Discourse Flow Analysis. Journal of Constructivist Psychology, $23,195-230$.
Stiles, W. B. (1992). Describing Talk: A taxonomy of verbal response modes. SAGE Series in Interpersonal Communication. SAGE Publications.

Stiles, W. B., Shapiro, D. A., \& Firth-Cozens, J. A. (1990). Correlations of session evaluations with treatment outcome. British Journal of Clinical Psychology, 29(1), 13-21. doi: 10.1111/j.2044-8260.1990.tb00844.x

Trijsburg, R. W., Frederiks, G. C. F. J., Gorlee, M., Klouwer, E., Hollander, A. M., \& Duivenvoorden, H. J. (2002). Development of the comprehensive psychotherapeutic interventions rating scale (CPIRS). Psychotherapy Research, 12, 287-317. doi:10.1093/ptr/12.3.287

Valdés, N., Tomicic, A., Pérez, J. C., \& Krause, M. (2010). Sistema de Codificación de la Actividad Terapéutica (SCAT1.0): Dimensiones y categorías de las acciones comunicacionales de pacientes y psicoterapeutas [Therapeutic Activity Coding System (TACS-1.0): Dimensions and Categories of Clients' and Psychotherapists' Communicative Actions]. Revista Argentina de Clínica Psicológica, 19, 117-129. Retrieved from: http://www.clinicapsicologica.org.ar/

Valdés, N., Krause, M., \& Álamo, N. (2011). ¿Qué Dicen y Cómo lo Dicen?: Análisis de la comunicación verbal de pacientes y terapeutas en episodios de cambio [What do they say and how do they say it? Analysis of patients' and therapists' verbal communication in change episodes]. Revista Argentina de Clínica Psicológica, 20, 15-28. Retrieved from: http://www.clinicapsicologica.org.ar/

Watzke, B., Koch, U., \& Schulz, H. (2006). Zur theoretischen und empirischen Unterschiedlichkeit von therapeutischen Interventionen, Inhalten und Stilen in psychoanalytisch und verhaltenstherapeutisch begründeten Psychotherapien [About theoretical and empirical differences in therapeutic interventions, contents and styles, in psychoanalytical and behavioral grounded psychotherapies]. Psychotherapie Psychosomatik Medizinische Psychologie, 56(6), 234-248.

Received July 10, 2012

Revision received November 25, 2012 Accepted December 28, 2012 